\title{
COMITÊS DE BACIAS HIDROGRÁFICAS E A GESTÃO PARTICIPATIVA DOS RECURSOS HÍDRICOS NO ESTADO DE MATO GROSSO
}

\author{
Leandro Obadowiski Bruno \\ Secretaria de Estado de Meio Ambiente-SEMA, Cuiabá, MT \\ obadowiski@gmail.com \\ Ibraim Fantin-Cruz \\ Universidade Federal de Mato Grosso, Programa de Pós-Graduação em Recursos Hídricos, Cuiabá, MT \\ ibraimfantin@gmail.com
}

\begin{abstract}
RESUMO
Os Comitês de Bacias Hidrográficas ( $\mathrm{CBHs}$ ) são órgãos colegiados que possibilitam a participação de diversos atores da sociedade na gestão dos recursos hídricos de modo a discutir, mediar e resolver conflitos pelo uso da água. Neste sentido, este trabalho tem por objetivo realizar um diagnóstico sobre a gestão dos recursos hídricos em Mato Grosso com foco na atuação dos comitês de bacias hidrográficas estaduais. O procedimento metodológico consistiu no levantamento de documentos oficiais pertinentes ao assunto. Como resultados, são apresentados o Sistema de Gestão de Recursos Hídricos de Mato Grosso, quantos e quais são os CBHs instituídos e em funcionamento, quais foram os temas mais debatidos, os principais conflitos e ações preventivas frente as incertezas climáticas. Conclui-se que as ações desenvolvidas por este órgão colegiado contribuem para a gestão participativa e descentralizadas, porém ainda são incipientes no contexto estado, mas não exercendo efetivamente seu papel consultivo e deliberativo.
\end{abstract}

Palavras-chave: Gestão usos múltiplos. Conflito pelo uso da água. Gestão de recursos hídricos.

\section{WATERSHED COMMITTEES AND THE PARTICIPATORY MANAGEMENT OF WATER RESOURCES IN THE STATE OF MATO GROSSO}

\begin{abstract}
The Watershed Committees (WCs) are collegiate bodies that allow the participation of various actors of society in the management of water resources in order to discuss, mediate and resolve conflicts over water use. In this sense, this study objectives to make a diagnosis on water resources management in Mato Grosso focusing on the performance of state watershed committees The methodological procedure consisted of the collection of official documents related to the subject. As a result, the Mato Grosso Water Resources Management System is presented, how many and which are the WCs instituted and in operation, which were the topics most debated, the main conflicts and preventive actions in the face of climate uncertainties. It can be concluded that the actions developed by this collegiate body contribute to participatory and decentralized management, but are still incipient in the state context, but not effectively exercising its advisory and deliberative role.
\end{abstract}

Keywords: Multiple uses. Conflict over water use. Water resources management.

\section{INTRODUÇÃO}

A água é um dos recursos naturais de maior importância, sendo imprescindível para garantir a qualidade de vida e o desenvolvimento econômico e social da população, além de ser componente da paisagem e do meio ambiente (ANDRADE et al., 2008).

A partir da Constituição Brasileira de 1988, a questão das águas doces recebe uma nova leitura, a partir da qual são definidas leis, atos administrativos que determinam novas diretrizes para a União e os Estados Federados, deixando explícitas as competências de cada esfera em relação aos corpos d'água. Com base na Constituição Federal, em 8 de janeiro de 1997 foi sancionada a Lei Federal no 9.433 que instituiu a Política Nacional de Recursos Hídricos ou Lei das Águas (BRASIL, 1997) expressando literalmente o processo de

Caminhos de Geografia Uberlândia - MG $\quad$ v. 21, n. $73 \quad$ Mar/2020 $\quad$ p. 332-346 Página 332


incorporação da gestão da água ao processo de desenvolvimento humano e ambiental, e orientando a sua transversalização nas demais políticas públicas no país (MEDEIROS e CANALI, 2012).

Contudo, apesar de o país possuir disponibilidade quantitativa de recursos hídricos, e de apresentar uma política de gerenciamento bem organizada, ainda assim ocorrem problemas de escassez em termos de quantidade e de qualidade em algumas regiões (OLIVEIRA et al., 2015). Recentemente o país acompanhou o problema de falta de água em algumas das bacias hidrográficas de São Paulo, assim como nos outros estados da região Sudeste, como Minas Gerais, Rio de Janeiro e Espírito Santo (CIRILO, 2015). Como consequência desta realidade, Neto (2015) relatam que a população em grande parte da Região Metropolitana de São Paulo e em diversas cidades do estado de São Paulo sofreram com a falta de abastecimento de água, sendo o racionamento de água parte da realidade atual para esta população.

Diante da crise das águas, tem-se a necessidade de discutir quais são as ações desenvolvidas nas bacias hidrográficas brasileiras pelas instâncias competentes para realizar uma gestão eficaz dos recursos hídricos. Essa questão pode ser analisada mediante a implementação dos instrumentos previstos na legislação vigente, tidos como indicadores da gestão, pois devem proporcionar a implantação da Política de Recursos Hídricos tanto a nível Nacional quanto Estadual (PORTO e PORTO, 2008). Uma forma de realizar a gestão dos recursos hídricos envolvendo diversos atores da sociedade é através dos Comitês de Bacias Hidrográficas (CBHs). Este fundamento possibilita uma gestão das águas participativa e descentralizada.

Os CBHs apresentam-se como órgãos colegiados onde são debatidas as questões regionais referentes à gestão dos recursos hídricos. Ao viabilizar a participação de diversos atores da sociedade na gestão dos recursos hídricos de uma bacia hidrográfica por meio de $\mathrm{CBHs}$, as soluções de conflitos pelo uso da água assim como o planejamento ambiental tendem a ser solucionadas de forma legítima, sem necessidade de intervenção do estado, considerando que os próprios afetados é quem responderão pelas ações necessárias. De acordo com Kemerich et al. (2016), este mesmo lugar de participação, de cooperação e de construção de alianças é, também, um espaço de conflitos que emergem em virtude dos diferentes sujeitos que o compõem - diferentes interesses, diferentes posições na escala social e política, das formas de resistência, organização e participação.

No Estado de Mato Grosso os CBHs foram instituídos pela lei oㅡ 6.945/1997, que seguindo o modelo e premissas da Lei Federal, instituiu a Política Estadual de Recursos Hídricos de Mato Grosso (PERH), a qual criou o Sistema Estadual de Recursos Hídricos e as diretrizes para o gerenciamento das águas do Estado (MATO GROSSO, 1997). Desta maneira, concedeu ao poder público estadual, a competência de auxiliar a criação e a manutenção de $\mathrm{CBHs}$ em rios sob sua jurisdição. Apesar dos 20 anos de vigência da PERH, pouco se sabe sobre a existência e atuação dos CBHs estadual (ALVES et al. 2009), frente a expansão agrícola, hidrelétrica e urbana que o estado vem passando ao longo destas duas décadas.

Nesta perspectiva, tem-se por objetivo realizar um diagnóstico sobre a gestão dos recursos hídricos em Mato Grosso com foco na atuação dos comitês de bacias hidrográficas estaduais. Para isso, pretende-se responder as seguintes questões: (a) Quantos CBHs instituídos estão em funcionamento? (b) Quais são as principais demandas analisadas pelos CBHs? (c) Os CBHs discutem ações preventivas contra eventos hidrológicos críticos? Por fim, busca-se traçar um panorama sobre a atuação do $\mathrm{CBH}$ no estado, tendo em vista que se atravessa um momento de incertezas com relação à disponibilidade hídrica, em termos quantitativos e qualitativos.

\section{MATERIAL E MÉTODOS}

Para levantar o número de CBHs estaduais, assim como as suas atividades no âmbito da gestão dos recursos hídricos foram feitas consultas no site da Imprensa Oficial do Estado de Mato Grosso (IOMAT, 2018). Os termos de busca adotados foram "comitês de bacias hidrográficas", "política estadual dos recursos hídricos", "Ata de reunião", "deliberação" e "outorga", assim foi possível obter as Atas e Normas dos CBHs empossados no Estado de Mato Grosso. Para ordenar as manifestações contidas nas Atas de Reuniões dos CBHs, foi elaborado um quadro contendo os temas abordados e assuntos correlatos, quantificando-se o número de ocorrência de cada tema nas pautas de discussão, conforme classificação baseada em Godoy e Cruz (2016) e Kemerich et al. (2016). É importante destacar que somente os fragmentos de discurso que versaram sobre as ideias relativas ao objetivo deste trabalho foram considerados (Quadro 1).

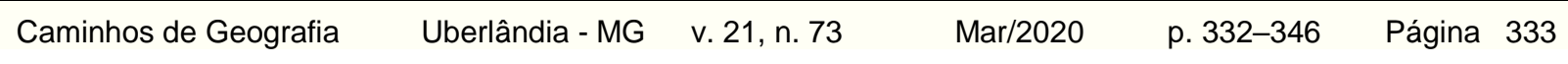


Quadro 1 - Definição dos temas abordados nas reuniões dos Comitês de Bacias Hidrográficas.

\begin{tabular}{|c|c|}
\hline Temas & Assuntos Correlatos \\
\hline Normativo & $\begin{array}{c}\text { Regulamentação regional de políticas de recursos hídricos: 1) cobrança pelo } \\
\text { uso da água; 2) Plano de bacia; 3) Barramento de cursos d'água em } \\
\text { propriedades rurais. }\end{array}$ \\
\hline Administrativo & $\begin{array}{l}\text { Autorregulamentação administrativa do Comitê: 1) composição/paridade; 2) } \\
\text { alteração do regimento interno; 3) recursos financeiros; desligamento dos } \\
\text { membros diante das faltas não justificadas. }\end{array}$ \\
\hline Educação Ambiental & $\begin{array}{l}\text { Realização de ações de educação ambiental nas bacias e divulgação do } \\
\text { comitê: 1) Palestras; 2) Cursos voltados à conscientização ambiental; }\end{array}$ \\
\hline $\begin{array}{l}\text { Licenciamento } \\
\text { Ambiental e Outorga de } \\
\text { uso da água }\end{array}$ & $\begin{array}{c}\text { Identificação de Empreendimentos em fase de licenciamento ambiental na } \\
\text { bacia. Definição de usuários da água através da outorga de uso da água: 1) } \\
\text { solicitação de informações dos processos de licenciamento ambiental e; 2) de } \\
\text { outorga ao órgão ambiental Estadual - SEMA/MT 3) consulta ao ministério } \\
\text { público estadual; }\end{array}$ \\
\hline $\begin{array}{l}\text { Qualidade Ambiental na } \\
\text { Bacia }\end{array}$ & $\begin{array}{c}\text { Identificação, discussão e apontamentos com relação às questões ambientais } \\
\text { de ocorrência na bacia: 1) disponibilidade hídrica; 2) qualidade da água; 3) } \\
\text { degradação das áreas de preservação ambiental como as nascentes e áreas } \\
\text { de preservação ambiental - APP; 4) resíduos sólidos; 5) processos erosivos; } \\
\text { 6) assoreamento; 7) conflito de uso e ocupação da terra; 8) recuperação de } \\
\text { áreas degradadas; }\end{array}$ \\
\hline Eventos & $\begin{array}{l}\text { Apoio e participação em eventos de gestão ambiental e de recursos hídricos: } \\
\text { 1) Apoio de programas ambientais; 2) participação de eventos técnico- } \\
\text { científicos, à exemplo de congressos e simpósios; }\end{array}$ \\
\hline $\begin{array}{l}\text { Estudos/ } \\
\text { Projetos/ Câmaras } \\
\text { Técnicas }\end{array}$ & $\begin{array}{l}\text { Debate, elaboração e participação de Planos, Projetos e Câmaras Técnicas } \\
\text { envolvendo ações a serem desenvolvidas na bacia: 1) câmara técnica para } \\
\text { barramento de cursos d'água; 2) câmara técnica para elaboração de plano de } \\
\text { bacia; 3) projetos de recuperação de áreas degradadas; 4) Fórum de } \\
\text { agrotóxicos; Ampliação da área de atuação do CBH; 5) projeto de pagamento } \\
\text { por serviços ambientais; Câmara Técnica para análise de Projetos (CTAP); 6) } \\
\text { Projetos de diagnósticos e educação ambiental na bacia; }\end{array}$ \\
\hline
\end{tabular}

Uma vez identificados os $\mathrm{CBHs}$ estaduais, assim como definidas as suas respectivas atividades, procedeuse com a espacialização geográfica dos mesmos, considerando uma base organizacional que contempla as bacias hidrográficas como Unidades de Planejamento e Gerenciamento (UPGs) do Sistema Estadual de Recursos Hídricos. As operações necessárias para esta etapa foram processadas em meio digital com auxílio do Sistema de Informação Geográfica de acesso livre GRASS GIS - versão 7.2 (GRASS DEVELOPMENT TEAM, 2016). Para isso, foi aplicada a metodologia apresentada por Bruno (2017), por meio da qual se descreve o procedimento automático de delimitação de bacias hidrográficas com o uso de software específico e dados matriciais, disponibilizados de forma aberta na internet. Tais características permitem agregar vantagens interessantes ao estudo, como versatilidade e segurança. Em posse dos limites físicos das bacias hidrográficas e considerando os marcos geográficos dos $\mathrm{CBHs}$, consultados previamente nos documentos levantados, mapeou-se então sua área de abrangência utilizando o Sistema de Informação Geográfica de acesso livre QGIS - Versão 2.14.3 Essen (QGIS DEVELOPMENT TEAM, 2017) conforme procedimentos reportados por Bossle (2015).

\section{RESULTADOS E DISCUSSÃO}

\section{A Gestão dos Recursos Hídricos em Mato Grosso}

O Sistema Estadual de Recursos Hídricos (SERH), criado pela Lei Estadual oㅡ 6.945 de 1997, é composto pelo Órgão Gestor/Coordenador, exercida pela Secretaria de Estado do Meio Ambiente (SEMA), entidades colegiadas, formada pelo Conselho Estadual dos Recursos Hídricos (CEHIDRO) e CBHs (Figura 1). Diferente do Sistema Nacional de Gerenciamento de Recursos Hídricos o SERH não prevê em sua composição a entidade Agência de Águas.

Caminhos de Geografia Uberlândia - MG $\quad$ v. 21, n. $73 \quad$ Mar/2020 $\quad$ p. 332-346 Página 334


Figura 1 - Sistema Estadual de Recursos Hídricos do Estado de Mato Grosso, e unidades administrativas da Secretaria de Estado do Meio Ambiente com funções de planejamento e gestão dos recursos hídricos.

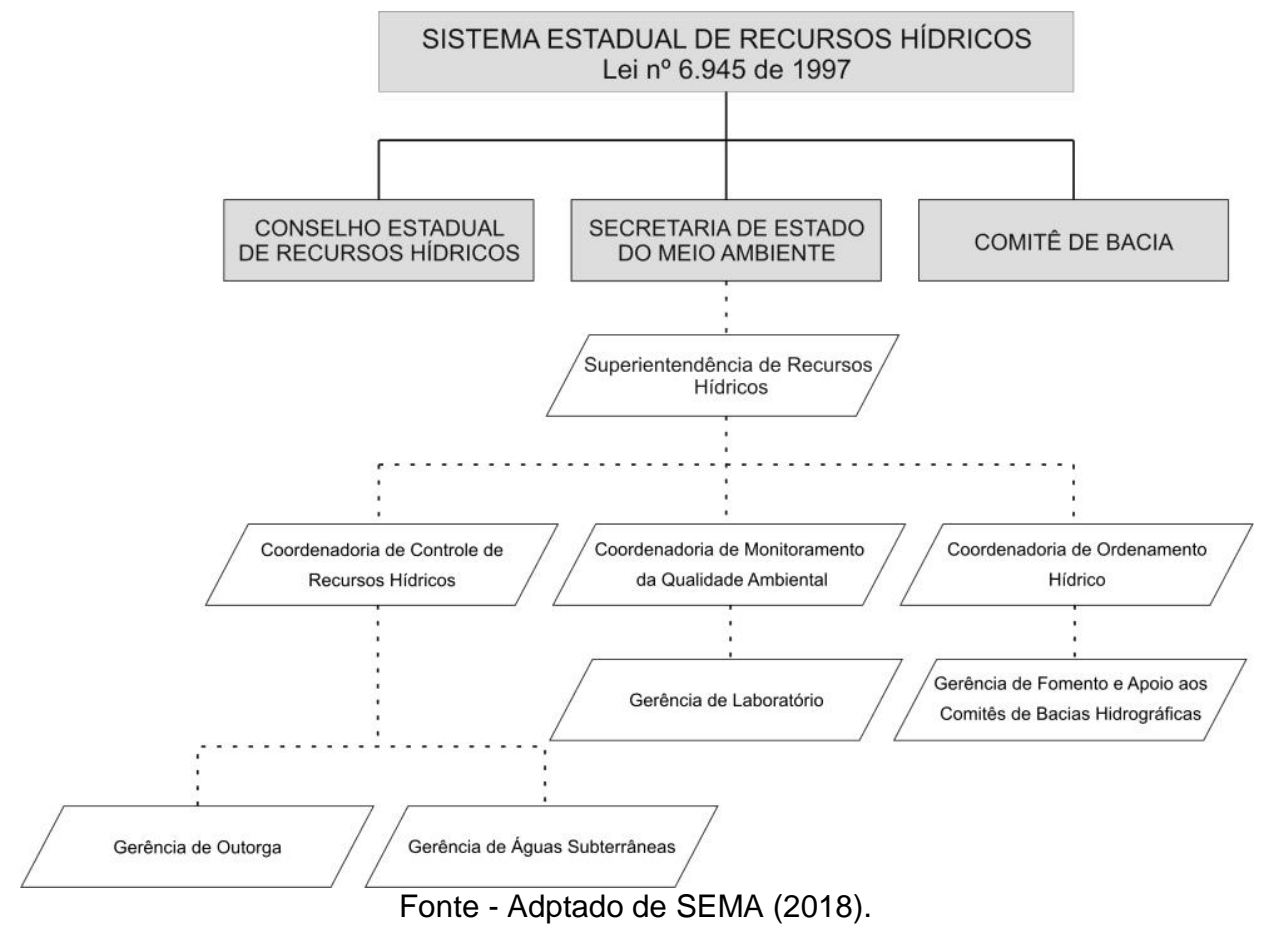

Na SEMA o artigo 98 do Decreto o 642 de 21/07/2016, que aprovou o seu Regimento Interno, traz como missão da Superintendência de Recursos Hídricos a de assegurar oferta de recursos hídricos em quantidade e qualidade na rede hidrográfica do Estado, promovendo a gestão integrada, descentralizada e participativa, além de subsidiar a formação e implementar a Política Estadual de Recursos Hídricos (PERH), e fomentar a criação e a manutenção dos CBHs Estaduais. Esta Superintendência é formada por três Coordenadorias e quatro Gerências, sendo uma exclusiva de Fomento e Apoio aos CBHs (Figura 1).

Ao CEHIDRO, ativo desde o ano de 2003, sendo anteriormente regulamentado pelos Decretos $n=3.952$, de 06 de março de 2002 , no 6.822, de 30 de novembro de 2005 e nํ․ 2.707, de 28 de julho de 2010, revogados pelo Decreto ํo 316 de novembro de 2015 (MATO GROSSO, 2015a), cabe as funções normativas, deliberativas e consultivas pertinentes à formulação, implantação e acompanhamento da PERH. Insta destacar que o CEHIDRO reúne órgãos governamentais, sociedade civil e usuários, de modo a discutir a gestão dos recursos hídricos no Estado para otimizar a sua utilização e também evitar o surgimento de conflitos futuros.

Com relação às atribuições dos $\mathrm{CBHs}$ a $\mathrm{PERH}$ determina à estes órgãos colegiados a possibilidade de promover o debate das questões relacionadas aos recursos hídricos e a devida articulação das entidades intervenientes; os estudos e a discussão dos planos que poderão ser executados na área da bacia; as ações de entendimento, cooperação, fiscalização e eventual conciliação entre usuários competidores pelo uso da água da bacia; ou também propor ao órgão gestor ações imediatas quando ocorrerem situações críticas; ou ainda sugestões ou alternativas para a aplicação da parcela regional dos recursos arrecadados pelo FEHIDRO (Fundo Estadual de Recursos Hídricos) na região hidrográfica e critérios de utilização da água. Contudo a PERH não prevê o poder deliberativo para normativas que envolvam critérios de outorga de utilização dos recursos hídricos, enquadramento dos corpos d'águas e participação na elaboração direta dos planos de usos das bacias. De modo a preencher esta lacuna, a SEMA, por meio da Portaria n.. 199 , de 16 de Novembro de 2010 (MATO GROSSO, 2010a), concedeu competências deliberativas aos CBHs com relação aos itens expressos no Art. 21 da PERH, além de versar sobre o enquadramento de corpos d'água em classes de uso e a cobrança pelo uso da água, observando o Art. 15 da Lei 6.945/97 para a definição de valores. Esta Portaria foi regulamentada pelo Governo Estadual pelo Decreto ํㅡ 695, de 15 de Setembro de 2016 (MATO GROSSO, 2016a).

O FEHIDRO foi extinto e substituído pela FEMAM (Fundo Estadual de Meio Ambiente), pela Lei complementar no 214, de 23 de junho de 2005, que criou a Secretaria de Estado do Meio Ambiente (MATO

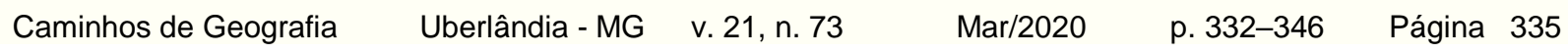


GROSSO, 2005). O FEMAM tem como objetivo financiar a implementação de ações visando a restauração ou reconstituição de bens lesados, a defesa do meio ambiente, a regularização de unidades de conservação, a política florestal e de recursos hídricos, a educação ambiental, as despesas com custeio e investimentos, incluindo encargos de capacitação, aperfeiçoamento, desenvolvimento e modernização de atividades ambientais. Os recursos financeiros provenientes de transferências da União, de Estados ou de países vizinhos e também dos recursos provenientes da cobrança pelo uso da água serão destinados exclusivamente à execução de planos e programas de recursos hídricos de interesse comum e implementação da Política Estadual de Recursos Hídricos, observadas as diretrizes fixadas na legislação federal.

Como visto, a PERH apresenta limitações que dificultam a implementação efetiva da gestão descentralizada, integrada e participativa, bem como divergências em relação a Política Nacional de Recursos Hídricos (Lei 9.433 de 1997). Por este motivo desde 2011 a PERH passa por um processo de revisão conduzido pela SEMA, na qual culminou em março de 2018 em uma minuta de lei enviada para a Casa Civil. Atualmente a minuta encontra-se na Assembleia Legislativa para apreciação dos deputados. As principais alterações proposta na minuta são: atribuição de competência deliberativa e normativa aos $\mathrm{CBHs}$, previsão de planos de recursos hídricos como instrumento de gestão, criação da Agência de Água no SERH e a recriação do FEHIDRO.

\section{Comitês de Bacias e suas atuações}

O Estado de Mato Grosso possui $10 \mathrm{CBHs}$ instalados e em funcionamento em rios sob seu domínio (Figura 2), destes os CBHs do Sepotuba (MATO GROSSO, 2010b), São Lourenço (MATO GROSSO, 2013a), Cuiabá ME (MATO GROSSO, 2015b), Cabaçal (MATO GROSSO, 2015c) e Jauru (MATO GROSSO, 2016b) estão inseridos na Região Hidrográfica Paraguai, os CBHs Baixo Teles Pires ME (MATO GROSSO, 2013b), Alto Teles Pires MD (MATO GROSSO, 2015d) e Médio Teles Pires (MATO GROSSO, 2016c) na Região Hidrográfica Amazônica, e os CBHs do Covapé (MATO GROSSO, 2003) e Alto Araguaia (MATO GROSSO, 2018) na Região Hidrográfica Tocantins-Araguaia.

Figura 2 - Localização dos Comitês de Bacias Hidrográficas (CBHs) nas Unidades de Planejamento e Gerenciamento de Recursos Hídricos (UPGS) de Mato Grosso.

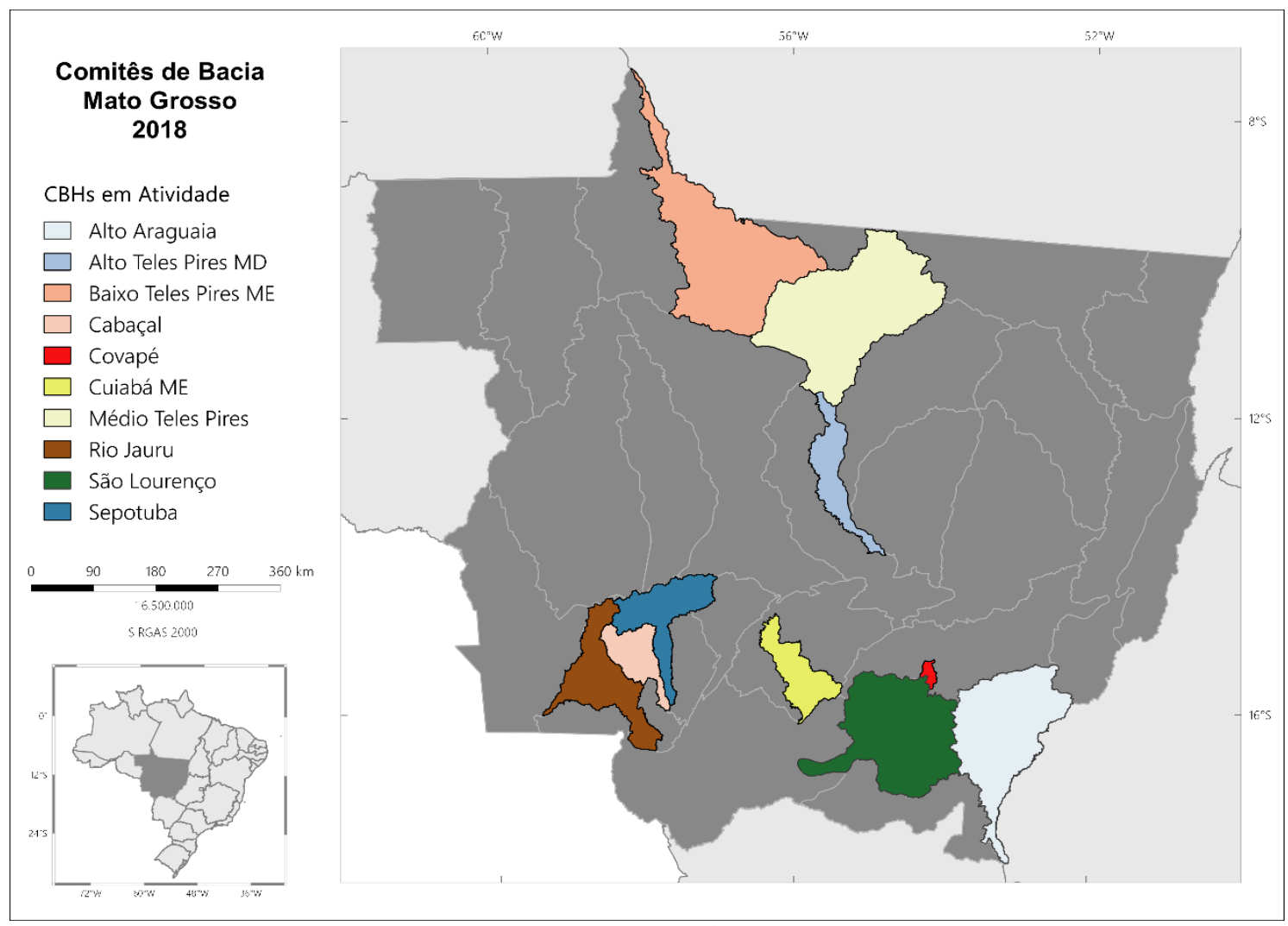

Fonte - Adptado de MATO GROSSO (2006). 
O CBH-Covapé, localiza-se na UPG Alto Rio das Mortes em área de fronteira agrícola, foi o primeiro CBH instituído no Estado, motivado pela utilização desordenada dos recursos hídricos por irrigantes. Esse processo resultou em conflito pelo uso da água e à necessidade de entendimento entre os usuários para viabilizar suas atividades (ALVES et al., 2009). O CBH-Covapé tem a função de gerenciar o uso dos recursos hídricos de forma racional e em consonância com a PERH nas microbacias hidrográficas dos Ribeirões do Sapé e Várzea Grande de modo a viabilizar a atividade de agricultura irrigada com os demais usos. $\mathrm{O}$ assunto mais debatido neste $\mathrm{CBH}$ relaciona-se aos atos normativos quanto à proposição de ampliação da sua área de atuação visando abranger toda a UPG Alto Rio das Mortes. De igual forma, debate-se a divulgação e/ou participação de seus membros em eventos técnico-científicos (Tabela 1).

Tabela 1 - Assuntos debatidos pelos Comitês de Bacias Hidrográficas no Estado de Mato Grosso entre a data de criação e dezembro de 2018.

\begin{tabular}{|c|c|c|c|c|c|}
\hline \multirow[b]{2}{*}{ Temas Debatidos } & \multicolumn{5}{|c|}{ Comitês de Bacias Hidrográficas - $\mathrm{CBHs}$} \\
\hline & Covapé & Sepotuba & $\begin{array}{l}\text { Baixo } \\
\text { Teles } \\
\text { Pires }\end{array}$ & $\begin{array}{c}\text { São } \\
\text { Lourenço }\end{array}$ & $\begin{array}{c}\text { Alto Teles } \\
\text { Pires }\end{array}$ \\
\hline Normativo & 0 & 8 & 0 & 1 & 2 \\
\hline Administrativo & 1 & 10 & 0 & 1 & 1 \\
\hline Educação Ambiental & 0 & 15 & 0 & 0 & 0 \\
\hline $\begin{array}{l}\text { Licenciamento Ambiental e } \\
\text { Outorga }\end{array}$ & 3 & 16 & 0 & 0 & 0 \\
\hline $\begin{array}{l}\text { Qualidade Ambiental na } \\
\text { Bacia }\end{array}$ & 2 & 13 & 1 & 2 & 2 \\
\hline Eventos & 5 & 10 & 2 & 3 & 7 \\
\hline $\begin{array}{c}\text { Estudos/ } \\
\text { Projetos/ Câmaras } \\
\text { Técnicas }\end{array}$ & 5 & 26 & 0 & 1 & 1 \\
\hline Total & 16 & 98 & 3 & 8 & 13 \\
\hline $\begin{array}{l}\text { Atas das reuniões } \\
\text { obtidas por } \mathrm{CBH}\end{array}$ & 6 & 35 & 4 & 4 & 8 \\
\hline
\end{tabular}

O CBH-Sepotuba, esta inserindo na UPG Alto Paraguai Médio, tem a função de gerenciar o uso dos recursos hídricos de forma racional e em consonância com a PERH da bacia hidrográfica do rio Sepotuba considerando o Licenciamento Ambiental de empreendimentos utilizadores de recursos naturais assim como a outorga de uso da água para tais atividades. Neste aspecto, destaca-se o debate, elaboração e participação de Planos, Projetos e Câmaras Técnicas envolvendo ações a serem desenvolvidas na bacia, a exemplo da criação de câmara técnica para elaboração de plano de bacia, projeto de recuperação de áreas degradadas, projeto de pagamento por serviços ambientais, e criação de Câmara Técnica para análise de Projetos (CTAP) e de diagnósticos e educação ambiental na bacia.

Estudos realizados na área de abrangência do $\mathrm{CBH}$ do Sepotuba indicam um alto potencial de comprometimento dos recursos hídricos, decorrentes da conversão da vegetação nativa em pastagens ou plantações agrícolas (SERIGATTO, 2006), degradação das áreas de preservação permanentes, contaminação dos recursos hídricos em razão de despejos de efluentes domésticos, assim como o transporte de sedimentos nos cursos d'água e o assoreamento de nascentes (GROSSI, 2006; SOUZA e NUNES, 2008). Há de se ressaltar ainda que a bacia do rio Sepotuba dispõe de significativo potencial energético, contanto com 28 empreendimentos inventariados, com capacidade de geração energética de aproximadamente $405 \mathrm{MW}$ (CTE, 2014). Deste total, quatro empreendimentos encontram-se em operação. Caracteriza-se por ser o CBH mais atuante do Estado de Mato Grosso, com 35 deliberações (Tabela 1).

Em 2015, a SEMA, em cumprimento à determinação judicial proferida nos autos da Ação Civil Pública no . 8497-30.2015.811.0055, em trâmite perante o Juízo da Quarta Vara Cível da Comarca de Tangará da Serra/MT, suspendeu temporariamente os processos de licenciamento e as suas respectivas licenças em fase de análise prévia e/ou instalação das PCH's na Bacia Hidrográfica do Rio Sepotuba, quais sejam, $\mathrm{PCH}$ - Jubinha II, PCH Jubinha III, PCH Juba IV, PCH Sepotuba, PCH Paiaguás, PCH Rio do Sapo, PCH Corredeiras, PCH Usina Velha, PCH Tapirapuã, PCH Salto Maciel e J. Malucelli Energia S/A (fase de termo de referência), ficando suspensas ainda as análises dos Termos de Referência de todo e qualquer

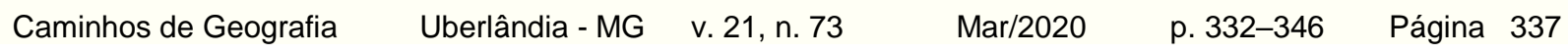


empreendimento hidrelétrico na Bacia Hidrográfica do Rio Sepotuba que estejam em fase de consulta à SEMA (MATO GROSSO, 2015f).

Para os outros $\mathrm{CBHs}$ foram obtidas poucas Atas de Reuniões, sendo registradas quatro para os $\mathrm{CBHs}$ Baixo Teles Pires ME, e para o CBH do São Lourenço, indicando uma baixa atuação, uma vez que estão em atividade há, pelo menos, três anos (Tabela 1). Identificou-se que o tema mais debatido em ambos os $\mathrm{CBHs}$ dizem respeito ao apoio e participação em eventos de gestão ambiental e de recursos hídricos dos seus membros. Destacam-se por apresentar as maiores áreas de abrangência dentre os $\mathrm{CBH}$ atuantes no Estado de Mato Grosso e também as menores densidades populacionais.

No ano de 2014 foi criado o CBH dos Afluentes da Margem Direita do Alto Teles Pires, em função da crescente demanda de utilização dos recursos hídricos em projetos de irrigação, poluição e contaminação da qualidade da água devido ao carreamento de agrotóxicos utilizados em larga escala pelo agronegócio da região (MATO GROSSO, 2015e). Nesta região, predomina o cultivo extensivo da soja, arroz e milho (MORENO e HIGA, 2005).

Para os CBHs do Cuiabá MD, Cabaçal, Alto Araguaia, Jauru e Médio Teles Pires não foram registrada atividades até dezembro de 2018. No entanto, este cenário vem sendo mudado com a adesão do Estado de Mato Grosso ao Programa Nacional de Fortalecimento dos Comitês de Bacias Hidrográficas (Procomitês), pactuado entre a ANA e a SEMA, por meio do Contrato oㅡ 075/2017 (ANA, 2017). Este programa tem o objetivo de contribuir para o aperfeiçoamento da capacidade operacional dos CBHs, bem como de promover a consolidação desses colegiados como espaços eficazes na elaboração das políticas de recursos hídricos, de forma descentralizada e participativa. Para isso, foram estabelecidos um conjuntos de indicadores e metas compatíveis com os diferentes estágios de implementação da gestão de recursos hídricos no âmbito dos diferentes CBHs.

Este programa foi concebido para ser implementado em um ciclo de cinco anos e prevê o aporte dos recursos financeiros, em parcelas anuais, que dependerão do cumprimento de metas acordadas entre representantes da ANA, CBHs, Conselho Estadual de Recursos Hídricos e SEMA. Para o desenvolvimento de atividades de apoio técnico, gerencial e administrativo às ações dos CBHs no âmbito do Procomitês, a SEMA estabeleceu o Chamamento Público 01/2018. Neste processo, resultou vencedor o Centro de Pesquisa do Pantanal (CPP), qualificado como Organização da Sociedade Civil de Interesse Público (OSCIP), que firmou com a SEMA o Termo de Colaboração n.ำ 1486/2018/SEMA/MT (SEMA, 2018).

\section{Comitês de Bacias: formalidades e desafios}

Entre as atribuições asseguradas aos CBHs estão as reuniões, que na maioria das vezes são realizadas nos municípios sedes ou em caráter itinerante, considerando os demais municípios integrantes do $\mathrm{CBH}$ de modo a ampliar a participação social e compartilhamento das informações. Estas podem ocorrer de forma Ordinária, realizadas bimestralmente, totalizando o número de seis reuniões durante o ano, ou de forma Extraordinárias, realizadas a qualquer momento do ano quando forem necessárias.

Os $\mathrm{CBHs}$ possuem obrigatoriamente sua composição tripartite, formadas pelo Poder Público e pelos Usuários de Recursos Hídricos e Sociedade Civil Organizada. Dentre os CBHs atuantes, o segmento de menor representatividade é o das Comunidades Indígenas, o qual possui apenas um representante, integrante do $\mathrm{CBH}$-Sepotuba. Com relação aos membros do poder público, os órgãos municipais se destacam devido às maiores representatividades nos $\mathrm{CBHs}$ (Tabela 2).

Tabela 2 - Composição dos Comitês de Bacias Hidrográficas.

\begin{tabular}{|c|c|c|c|c|c|c|c|c|}
\hline \multirow[b]{2}{*}{ के } & \multirow[b]{2}{*}{ Membros } & \multicolumn{7}{|c|}{ Comitês de Bacias Hidrográficas - CBHs } \\
\hline & & Covapé & Sepotuba & $\begin{array}{l}\text { Baixo } \\
\text { Teles } \\
\text { Pires }\end{array}$ & $\begin{array}{c}\text { São } \\
\text { Lourenç } \\
\text { o }\end{array}$ & $\begin{array}{l}\text { Alto } \\
\text { Teles } \\
\text { Pires }\end{array}$ & Cabaçal & Cuiabá \\
\hline \multirow{3}{*}{ 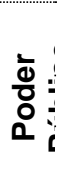 } & $\begin{array}{l}\text { Poder Público } \\
\text { Municipal }\end{array}$ & 02 & 06 & 07 & 07 & 04 & 11 & 09 \\
\hline & Poder Público Estadual & 04 & 03 & 03 & 01 & 04 & 01 & 03 \\
\hline & Poder Público Federal & - & - & - & 02 & 03 & - & 02 \\
\hline \multirow{2}{*}{ कू. } & Abastecimento Público & 01 & - & 01 & 01 & 01 & - & 01 \\
\hline & Indústria & - & 03 & 01 & 01 & 03 & 01 & 02 \\
\hline
\end{tabular}

$\begin{array}{lllll}\text { Caminhos de Geografia } \quad \text { Uberlândia - MG } & \text { v. 21, n. } 73 \quad \text { Mar/2020 } & \text { p. 332-346 } & \text { Página } 338\end{array}$




\begin{tabular}{llllllll} 
Uso Agropecuário & 03 & 02 & 03 & - & 03 & 01 & 01 \\
\hline Hidroeletricidade & - & 01 & 01 & 01 & - & 02 & 02 \\
\hline $\begin{array}{l}\text { Comunidades } \\
\text { Indígenas }\end{array}$ & - & 01 & - & - & - & - & - \\
\hline $\begin{array}{l}\text { Pesca, Turismo, Lazer } \\
\text { e outros usos não } \\
\text { consultivos }\end{array}$ & 01 & 01 & - & 01 & - & - & - \\
\hline $\begin{array}{l}\text { Organizações da } \\
\text { Sociedade Civil de } \\
\text { Interesse Público }\end{array}$ & - & 02 & 03 & 01 & 02 & 02 & 01 \\
\hline $\begin{array}{l}\text { Organizações de } \\
\text { Ensino e Pesquisa }\end{array}$ & - & - & - & 01 & - & 03 & 01 \\
\hline $\begin{array}{l}\text { Entidades Técnico- } \\
\text { Profissionais }\end{array}$ & 01 & - & 02 & 05 & - & 01 & 06 \\
\hline $\begin{array}{l}\text { Organizações não } \\
\text { governamentais }\end{array}$ & - & - & - & 01 & 02 & 02 & 01 \\
\hline Total & $\mathbf{1 2}$ & $\mathbf{1 9}$ & $\mathbf{2 1}$ & $\mathbf{2 2}$ & $\mathbf{2 2}$ & $\mathbf{2 4}$ & $\mathbf{2 8}$
\end{tabular}

Nas pautas das reuniões são discutidos os problemas socioambientais verificados na bacia, a descentralização dos recursos hídricos, a resolução de conflitos, a participação dos membros em congressos e participação em cursos ministrados pelo comitê e outros órgãos, entre outros assuntos relacionados diretamente ou indiretamente ao comitê.

Nenhum dos CBHs do Estado de Mato Grosso possui plano de bacia, a ausência deste instrumento limita as discussões sobre ações prioritárias a serem desenvolvidas e, consequentemente, reduz a possibilidade de tomada de decisão, à exemplo das questões relacionadas a cobrança pelo uso da água, proposta de enquadramento dos corpos hídricos superficiais e ao aperfeiçoamento do arranjo institucional. Talvez, por esta razão, as reuniões realizam-se com forte viés educativo. Assim sendo, evidencia-se uma gestão participativa e descentralizada, contudo os $\mathrm{CBHs}$ ainda não exercem efetivamente seu poder consultivo e deliberativo. A ausência de um plano de bacia dificulta as atividades inerentes aos Estudos/Projetos/Câmaras Técnicas, fazendo com que os comitês exerçam uma relação de dependência técnica com o Órgão Gestor, demonstrada pela frequência com que estes órgãos colegiados solicitam informações de processos de licenciamento ambiental e de outorga. Esta característica pode estar relacionadas à um sistema de informação dos recursos hídricos deficitário por parte do Órgão Gestor/Coordenador.

Assim como observado no Estado de Mato Grosso, o papel consultivo e deliberativo dos CBHs em outros Estados da Federação também é questionado. Segundo loris (2010), este órgão estabeleceram um ambiente democrático e descentralizado baseado em mecanismos rígidos, hierarquizados e que servem aos grupos com maior força política, ressaltando ainda que decisões mais estratégicas e com maior impacto sobre os recursos hídricos continuam nas mãos de outras instâncias políticas, notadamente a equipe econômica do governo, como aconteceu no caso das hidrelétricas no rio Madeira em 2007. Por consequência, acaba ocorrendo uma falsa impressão de que os caminhos tomados no setor são originários de um consenso a partir de uma diversidade de opiniões e concepções previamente debatidas (SCANTIMBURGO, 2016). Ainda neste tocante, Spinola et al. (2016) destacam o caso do CBH do Rio São Francisco (CBHSF), onde as ações de aprovação do projeto de transposição pelo Conselho Nacional de Recursos Hídricos, a liberação da outorga preventiva pela ANA e a liberação da licença pelo IBAMA aconteceram à revelia do que recomendou o CBHSF. Moretti e Marinho (2013) salientam ainda as limitações e desafios atribuídos aos $\mathrm{CBHs}$ existentes e aos que estão sendo criados, pois há disputas setoriais na aplicação de investimento financeiro na execução das ações previstas que, muitas vezes, são em favor de interesses econômicos e da iniciativa privada.

Um aspecto a se considerar na gestão dos recursos hídricos em Mato Grosso é quanto às especificidades regionais, como as situações dos rios amazônicos e do pantanal. Nestes casos faz-se necessário a identificação dos atores sociais envolvidos direta ou indiretamente nestes biomas, que tradicionalmente utilizam das águas para as suas necessidades básicas (MORETTI e MARINHO, 2016). Assim, torna-se imprescindível a participação do órgão gestor e dos $\mathrm{CBHs}$ na inclusão dos atores usuários das águas das comunidades tradicionais (ribeirinhos, pescadores, quilombolas, povos indígenas) e assentados. 
Quanto à obtenção das Atas e acesso ao endereço eletrônico da SEMA/MT para obtenção dos dados, constaram-se limitações do Órgão Gestor e Comitês de Bacias em publicizar as atividades relacionadas às reuniões dos CBHs. De modo a ilustrar tal situação, Empinotti et al. (2015) apontaram, por meio de avaliação da disponibilização de informação dos órgãos gestores responsáveis pela gestão da água dos 26 estados brasileiros e do distrito federal em suas páginas eletrônicas na internet que, dentre os Estados analisados, Mato Grosso detém a 14a posição no ranking que elenca os níveis de transparência dos recursos hídricos para o ano de 2015. Não se pode ouvidar que o acesso à informação e conhecimento se tornaram chaves como estratégias para influenciar a tomada de decisão. Ao expor os problemas por meio de divulgação de dados, é possível aumentar o controle sobre os atores responsáveis pela execução de ações e os seus resultados, uma vez que muitos dos problemas ambientais contemporâneos são identificados e tratados a partir da divulgação de informações (EMPINOTTI et al., 2016). Referindo-se ao sistema de informações sobre recursos hídricos na SEMA, Noquelli (2016) aponta que este instrumento está sendo trabalhado, contando atualmente com banco de dados isolados.

O Estado de Mato Grosso, no ano de 2017, aderiu ao 2ำ ciclo do PROGESTÃO (Programa de Consolidação do Pacto Nacional pela Gestão de Águas), que é um programa de incentivo financeiro aos sistemas estaduais para aplicação exclusiva em ações de fortalecimento institucional e de gerenciamento de recursos hídricos, mediante o alcance de metas acordadas entre o órgão gestor e a Agência Nacional da Água ANA (MATO GROSSO, 2017). A diferença desse segundo ciclo em relação ao anterior é o acréscimo das metas de investimentos. Assim, se o estado comprovar a aplicação de recursos com orçamento próprio de até $\mathrm{R} \$ 250$ mil, a ANA pagará igual valor ao estado. Essa meta financeira está relacionada à aplicação de recursos estaduais em alguma das variáveis consideradas críticas para a gestão da água, como organização institucional do modelo de gestão; comunicação; planejamento estratégico; plano estadual de recursos hídricos; sistema de informações; outorga; e fiscalização (ANA 2017). Por intermédio deste programa, em 2018 foi iniciada a elaboração do primeiro Plano de Bacia Hidrográfica para as UPGs do Alto Paraguai Superior e do Alto Paraguai Médio, com previsão de conclusão em janeiro de 2021.

Embora detenha um papel fundamental na gestão de recursos hídricos, os $\mathrm{CBHs}$ ainda não recebem a atenção que merecem, seja por desconhecimento da população, seja pela visão imediatista de seus representantes, ou ainda, por falta de recursos que permitam uma maior divulgação do trabalho realizado. Assim, atitudes com caráter pedagógico e modificador podem construir um caminho objetivando a cooperação pelas águas (SOUZA; e SILVEIRA, 2016).

\section{Eventos hidrológicos críticos}

O Estado de Mato Grosso possui uma ampla diversidade ambiental proporcionada pelos fatores bióticos e abióticos. Em seu domínio estão inseridos três importantes biomas brasileiros: a Floresta Amazônica, o Cerrado e o Pantanal. E uma vasta área de transição entre Floresta e Cerrado, denominada Ecótono. Apresenta um extenso sistema de drenagem, conhecido por abrigar as nascentes de três relevantes bacias hidrográficas: Platina, Amazônica e Araguaia-Tocantins. Caracteriza-se ainda por uma precipitação média que pode variar entre 1.200 a 2.000 mm/ano (DALLA NORA e NETTO, 2012; SOUZA et al., 2013).

Mato Grosso é, portanto, bem dotado de águas, tanto superficiais como subterrâneas, não apresentando regiões áridas ou semiáridas. Desse modo, as crises hídricas só poderão ser provenientes de estiagens, citados por (NETO, 2015) como fenômenos hidrometeorológicos naturais presentes na variabilidade cíclica das precipitações que incidem sobre determinada região. O seu agravamento será resultante de uma gestão dos recursos hídricos ineficiente, com ausência de investimentos em sistemas de abastecimento de água e desencadeada pela falta de educação da população para as questões ambientais.

É imperativo que se discuta a gestão dos recursos hídricos de modo a se evitar os problemas da falta de água, ainda que as características ambientais do Estado de Mato Grosso engendrem a ideia de abundância dos recursos hídricos. Neste tocante, é salutar destacar que a crise da água é uma constante em alguns Estados da Federação, ainda que estes disponham de regular disponibilidade hídrica ou detenha relativo desenvolvimento econômico e estrutural, a exemplo do Estado de São Paulo. Neste aspecto, Morengo e Alves (2015) citam que a combinação de baixos índices pluviométricos durante o verão 2014 e 2015 e um grande crescimento da demanda de água, assim como a ausência de um planejamento minimamente adequado para o gerenciamento dos recursos resultou na chamada "crise hídrica" naquela região. Conforme Couceiro et al. (2010) relatam, a escassez da água pode ser considerada um problema de cunho nacional generalizado. Para o referido autor, os recursos hídricos disponíveis estão sendo comprometidos em quase todas as regiões do país, devido à degradação urbana, industrial ou agrícola, e por outros desequilíbrios resultantes do desmatamento, poluição e uso indevido do solo, inclusive na Amazônia.

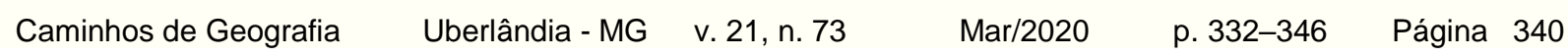


Outra característica que evidencia o Estado de Mato Grosso quanto a gestão dos recursos hídricos é a elevada taxa decrescimento econômico e aumento de áreas urbanas, impulsionados pela produtividade agropecuária e expansão das indústrias ligadas ao agronegócio. Ao tratar sobre o consumo de água destinada à agricultura, é importante mencionar que os sistemas produtivos agrícolas demandam cerca de $70 \%$ da água coletada no mundo, sendo a atividade produtiva que mais consome água no planeta. A tendência de uso da água para as atividades agrícolas é evolutiva, considerando-se o avanço das áreas de fronteiras do agronegócio, o aumento da produtividade diante das inovações nas alternativas tecnológicas para agricultura de precisão e também da incorporação da irrigação aos novos territórios de produção. Com relação às atividades agrícolas e o consumo de água para as suas atividades ANA (2016) mencionam que a irrigação brasileira tem crescido a taxas médias anuais entre 4,4\% e 7,3\% desde a década de 1960, sendo Mato Grosso o segundo Estado brasileiro em produção agrícola, com $24 \%$ de tudo o que o Brasil produz de grãos (CONAB, 2014). Os polos de pivôs centrais localizam-se nas UPG's Alto Rio das Mortes com 234 equipamentos instalados, Alto Teles Pires com 178 equipamentos e Arinos com 50 equipamentos, somando 56.000 hectares irrigados por pivôs centrais nestas regiões para o ano de 2014 (Figura 3). Como consequência deste crescimento econômico pautado em atividades utilizadoras de recursos naturais, sobretudo para atividades caracterizadas pelas elevadas taxas de utilização da água em seu processo produtivo, as bacias hidrográficas ficam propensas aos problemas ambientais de ordem hídrica. Estudos realizados por Possavatz et al. (2014), Hunke et al. (2015) e Rocha (2015) apontam para a possibilidade de assoreamento do leito dos rios ou a diminuição da disponibilidade hídrica em quantidade e qualidade para diversos usos, a supressão da vegetação nativa e a redução da qualidade ambiental que afeta diretamente a qualidade de vida da população em Mato Grosso.

No mês de Outubro de 2016 a região hidrográfica do rio Queima-Pé, em Tangará da Serra, apresentou crise hídrica por apresentar falta de água para o abastecimento para consumo humano e animal, e também para suprir a necessidade da produção agropastoril, industrial e comercial do Município, fato que resultou no Decreto $n .$. 351, de 20 de Outubro de 2016, declarando situação de emergência neste município, afetado por estiagem (TANGARÁ DA SERRA, 2016).

\section{CONSIDERAÇÕES FINAIS}

A existência de um Órgão Gestor estruturado e da atuação de dez CBHs abrangendo os três biomas Matogrossenses oportunizam o fortalecimento e o debate sobre as questões inerentes aos recursos hídricos, ainda que existam limitações nesta atuação como a falta de recursos financeiros, ausência de planos de bacias e reduzida efetividade quanto a publicização dos dados, que vem sendo superados pela adesão à programas de apoio a gestão de recursos hídricos como o Progestão e o Procomitês da Agência Nacional de Águas.

Algumas bacias hidrográficas sinalizam potenciais conflitos pelo uso da água, principalmente nas regiões destinadas à irrigação, como é o caso do $\mathrm{CBH}$ Alto Teles Pires - MD. Merecem atenção também àquelas áreas onde estão inventariadas uma quantidade significativa de usinas hidrelétricas, à exemplo do $\mathrm{CBH}-$ Sepotuba.

Em relação aos temas debatidos pelos $\mathrm{CBHs}$, foram identificadas as chamadas "crises hídricas" na microbacia do córrego Queima-pé em Tangará da Serra. Destaca-se que as atividades econômicas desenvolvidas no Estado exercem forte pressão sobre os recursos hídricos rurais e urbanos.

\section{AGRADECIMENTOS}

À Superintedência de Recursos Hídricos da Secretaria de Estado de Meio Ambiente de Mato Grosso (SEMA), pela disponibilização de dados e informações sobre sua estrutura e funcionamento.

\section{REFERÊNCIAS}

ALVES, E. C. R. F.; SILVINO, A. N. O.; ANDRADE, N. L. R.; SILVEIRA, A. Gestão dos recursos hídricos no Estado de Mato Grosso. Revista Brasileira de Recursos Hídricos, v. 14, n. 3, p. 69-80, 2009. https://doi.org/10.21168/rbrh.v14n3.p69-80

Caminhos de Geografia Uberlândia - MG $\quad$ v. 21, n. 73 $\quad$ Mar/2020 $\quad$ p. 332-346 Página 341


ANA - AGÊNCIA NACIONAL DAS ÁGUAS. Levantamento da Agricultura Irrigada por Pivôs Centrais no Brasil para o Ano de 2014. Brasília - DF, 2016. 33 ISBN 978-85-8210-034-9. Disponível em: < http:// https://is.gd/3JY68L >. Acesso em: 04 Jul. 2018.

Programa de Consolidação do Pacto Nacional pela Gestão das Águas - PROGESTÃO. 2017. Disponível em: < http:// http://progestao.ana.gov.br/ >. Acesso em: 29 Dez. 2018.

ANDRADE, N. L. R. D.; XAVIER, F. V.; ALVES, É. C. R. D. F.; SILVEIRA, A.; OLIVEIRA, C. U. R. D. Caracterização morfométrica e pluviométrica da bacia do Rio Manso-MT. Geociências (São Paulo), v. 27, n. 2, p. 237-248, 2008.

BOSSLE, R. C. QGIS e o geoprocessamento na prática. 1a edição. São José dos Pinhais: 2015. 232p. ISBN 978-85-918392-0-9.

BRASIL. Lei no 9.433, de 08 de janeiro de 1997. Institui a Política Nacional de Recursos Hídricos, cria - Sistema Nacional de Gerenciamento de Recursos Hídricos. Disponível em: <http://www.planalto.gov.br/ccivil_03/LEIS/L9433.htm>. Acesso em: 10 Jan. 2017.

BRUNO, L. O. GRASS: A free and open source solution for hydrographic body analysis. Nativa, v. 5, n. 1, p. 24 - 30, 2017. https://doi.org/10.5935/2318-7670.v05n01a04

CIRILO, J. A.. Crise hídrica: desafios e superação. Revista USP, n. 106, p. 45-58, 2015. https://doi.org/10.11606/issn.2316-9036.v0i106p45-58

CONAB - COMPANHIA NACIONAL DE ABASTECIMENTO. Levantamento sistemático da produção agrícola: pesquisa mensal de previsão e acompanhamento das safras agrícolas no ano civil. Brasília - DF, 2014. ISSN 2317-7535. Disponível em: < https://is.gd/vlxnFp >. Acesso em: 02 Fev. 2018.

COUCEIRO, S. R. M.; HAMADA, N.; FORSBERG, B. R.; PADOVESI-FONSECA, C. Effects of anthropogenic silt on aquatic macroinvertebrates and abiotic variables in streams in the Brazilian Amazon. Journal of Soils and Sediments, v. 10, n. 1, p. 89-103, 2010. ISSN 1439-0108. https://doi.org/10.1007/s11368-009-0148-z

CTE - CENTRO TECNOLÓGICO DE ENGENHARIA. Estudo de Impacto Ambiental do Complexo Hidrelétrico Juba. Goiânia - GO: Centro Tecnológico de Engenharia, 2014. Disponível em: < http://www.sema.mt.gov.br/index.php?option=com_docman\&task=cat_view\&gid=841\&ltemid=77>.

Acesso em: 09 Fev. 2018.

DALLA NORA, G.; NETTO, L. D. R. G. Características Políticas e Naturais dos Recursos Hídricos no Estado de Mato Grosso. Revista Geonorte v. 3, n. 4, p. 692-702, 2012.

EMPINOTTI, V. L.; JACOBI, P. R.; FRACALANZA, A. P. Transparência e a governança das águas. $\begin{array}{lllllll}\text { Estudos Avançados, } & \text { v. } 30, \quad \text { n. } & 88, & \text { p. } & 63-75, & \end{array}$ https://doi.org/10.1590/s0103-40142016.30880006

EMPINOTTI, V.; JACOBI, P. R.; FRACALANZA, A. P.; BUJAK, N. L.; JUNQUEIRA, L. B.; DE ABREU, M. A. Transparência na Gestão dos Recursos Hídricos no Brasil. Grupo de Acompanhamento e Estudos em Governança Ambiental - Govamb/lee; Universidade de São Paulo - Usp, 2015. Disponível em: < https://is.gd/2hOYG3 >. Acesso em: 11 Fev. 2018.

GODOY, V. N.; CRUZ, R. C. Autogestão dos Recursos Hídricos-Estudo de Caso da Bacia Hidrográfica do Rio Santa Maria-RS. Ciência e Natura, v. 38, n. 2, p. 980-997, 2016. https://doi.org/10.5902/2179460X21911

GRASS DEVELOPMENT TEAM. Geographic Resources Analysis Support System - GRASS GIS, 2016. Disponível em: < http://grass.osgeo.org/ >. Acesso em: 01 Fev. 2018.

GROSSI, C. H. Diagnóstico e monitoramento ambiental da microbacia hidrográfica do rio Queima-Pé, MT. 2006. 122 p. Tese (Doutorado). Universidade Estadual Paulista - UNESP, Botucatu - SP. 
HUNKE, P.; ROLLER, R.; ZEILHOFER, P.; SCHRÖDER, B.; MUELLER, E. N. Soil changes under different landuses in the Cerrado of Mato Grosso, Brazil. Geoderma Regional, v. 4, n. 0, p. 31-43, 2015. https://doi.org/10.1016/i.geodrs.2014.12.001

IOMAT- Imprensa Oficial do Estado de Mato Grosso. Diário Oficial. Cuiabá - MT, 2018. Disponível em: $<$ https://www.iomat.mt.gov.br/>.

IORIS, A. A. R. Da foz às nascentes: análise histórica e apropriação econômica dos recursos hídricos no Brasil. In: ALMEIDA, A. W. B. D. Capitalismo Globalizado e Recursos Territoriais. Lamparina: Rio de Janeiro, 2010, p. 211-255.

KEMERICH, P. D. D. C.; RITTER, L. G.; DULAC, V. F.; CRUZ, R. C. Gerenciamento de recursos hídricos: desafios e potencialidades do Comitê de Bacia Hidrográfica do Rio Passo Fundo. Revista Sociedade \& Natureza, v. 28, n. 1, 2016. https://doi.org/10.1590/1982-451320160106

MATO GROSSO. Lei no 6.945, de 05 de novembro de 1997. Dispõe sobre a Política Estadual de Recursos de Recursos Hídricos, institui o Sistema Estadual de Recursos Hídricos e dá outras providências. 1997. In: Diário Oficial de Mato Grosso oo 22259. Disponível em: < https://www.iomat.mt.gov.br/portal/visualizacoes/jornal/11922/\#/e:11922?find=Recursos\%20H\%C3\% ADdricos>. Acesso em: 10 Jan. 2017.

. Conselho Estadual de Recursos Hídricos. Resolução no 01, de 14 de novembro de 2003. Institui o Comitê das Sub-Bacias Hidrográficas dos Ribeirões do Sapé e Várzea Grande. 2003. In: Diário Oficial oㅡ 23787. Disponível em: https://www.iomat.mt.gov.br/verpdf/13440/\#/p:22/e:13440?find=cehidro. Acesso em: 14 Jan. 2018.

. Lei Complementar no 214 de 23 de junho de 2005. Cria a Secretaria de Estado do Meio Ambiente. Secretaria de Estado do Meio Ambiente. 2005. Disponível em: http://www.sema.mt.gov.br. Acesso em: 14 abr. 2018.

Conselho Estadual de Recursos Hídricos. Resolução n. 005 de 16 de Agosto de 2006. Institui a Divisão Hidrográfica do Estado de Mato Grosso. In: Diário Oficial n. 24417. Disponível em: < https://www.iomat.mt.gov.br/ver-pdf/961/\#/p:5/e:961 >. Acesso em: 10 Jan. 2017.

Portaria no 199 de 16 de novembro de 2010. Secretaria de Estado do Meio Ambiente SEMA. Concede aos Comitês de Bacias Hidrográficas - CBH a função deliberativa sobre suas competências. 2010a. Disponível em: http://www.sema.mt.gov.br. Acesso em: 27 ago. 2018.

Conselho Estadual de Recursos Hídricos. Resolução no 36, de 09 de setembro de 2010. In: Diário Oficial no 25407. Institui o Comitê de Bacia Hidrográfica do Rio Sepotuba. 2010b. Disponível em: < https://www.iomat.mt.gov.br/ver-pdf/2692/\#/p:18/e:2692?find=Sepotuba>. Acesso 27082018.

. Conselho Estadual de Recursos Hídricos. Resolução no. 55 de 09 de maio de 2013. Institui - Comitê de Bacia Hidrográfica São Lourenço. 2013a In: Diário Oficial № 26053. https://www.iomat.mt.gov.br/ver-pdf/3423/\#/p:10/e:3423?find=Comit\%C3\%AA\%20de\%20Bacia

. Conselho Estadual de Recursos Hídricos. Resolução o 53 de 09 de maio de 2013. Institui o Comitê de Bacia Hidrográfica dos Afluentes da Margem Esquerda do Baixo Teles Pires. 2013b. In: Diário Oficial no 26053. Disponível em: https://www.iomat.mt.gov.br/verpdf/3423/\#/p:10/e:3423?find=Comit\%C3\%AA\%20de\%20Bacia

. Decreto n. 316 de 06 de novembro de 2015. Regulamenta o Conselho Estadual de Recursos Hídricos do Estado de Mato Grosso. 2015a. In: Diário Oficial o 26668. Disponível em <http://www.sema.mt.gov.br/index.php?option=com_docman\&ltemid=282>. Acesso em: 17 mar. 2018.

Conselho Estadual de Recursos Hídricos. Resolução no 77, de 14 de maio de 2015. Institui o Comitê de Bacia Hidrográfica dos Afluentes da Margem Esquerda do Rio Cuiabá. 2015b. In: Diário Oficial $\quad \mathrm{n}^{\circ} \quad 26537 . \quad<\mathrm{https}: / / w w w . i o m a t . m t . g o v . b r / v e r-$ pdf/14083/\#/p:14/e:14083?find=Comit\%C3\%AA\%20de\%20Bacia>. Acesso em: 17 mar. 2018. 
Conselho Estadual de Recursos Hídricos. Resolução no 78, de 14 de maio de 2015. Institui o Comitê de Bacia Hidrográfica do rio Cabaçal. 2015c. In: Diário Oficial 26537. Disponível em: <https://www.iomat.mt.gov.br/ver-pdf/14083/\#/p:14/e:14083?find=Comit\%C3\%AA\%20de\%20Bacia>. Acesso em: 17 mar. 2018.

. Conselho Estadual de Recursos Hídricos. Resolução no 75, de 19 de março de 2015. Institui o Comitê de Bacia Hidrográfica dos Afluentes da Margem Direita do Alto Teles Pires. 2015d. In: Diário Oficial $\quad$ no $26504 . \quad<$ https://www.iomat.mt.gov.br/verpdf/3955/\#/p:15/e:3955?find=Comit\%C3\%AA\%20de\%20Bacia>. Acesso em: 17 mar. 2018.

. Comitê de Bacia Hidrográfica dos Afluentes da Margem Direita do Alto Teles Pires. Ata da 1a Reunião Ordinária. 2015e. In: Diário Oficial n. 26599. Disponível em: < https://is.gd/GKmdZL >. Acesso em: 14 Jan. 2018.

. Termo de Suspensão de Licenças Ambientais. In: Diário Oficial n. 26567. Disponível em: < https://www.iomat.mt.gov.br/verpdf/14120/\#/p:15/e:14120?find=Termo\%20de\%20Suspens\%C3\%A3o >. Acesso em: 11 Jan. 2018.

Decreto oㅡ 695 de 15 de Agosto de 2016. Reconhece os Comitês de Bacias Hidrográficas dos Rios de Domínio do Estado como integrantes do Sistema Estadual de Recursos Hídricos. 2016a. In: Diário Oficial no 26862. Disponível em: <https://www.iomat.mt.gov.br/verpdf/14625/\#/p:4/e:14625?find=Reconhece\%20os\%20Comit\%C3\%AAs\%20de\%20Bacias $>$. Acesso em: 17 mar. 2018.

. Conselho Estadual de Recursos Hídricos. Resolução no 86, de 19 de setembro de 2016. Institui o Comitê da Bacia Hidrografica do Rio Jauru. 2016b. In: Diário Oficial no 26864. Disponível em: <https://www.iomat.mt.gov.br/ver-pdf/14629/\#/p:17/e:14629?find=Comit\%C3\%AA\%20de\%20Bacia>. Acesso em: 17 mar. 2018.

. Conselho Estadual de Recursos Hídricos. Resolução no 87, de 19 de setembro de 2016. Institui o Comitê de Bacia Hidrográfica dos Afluentes do Médio Teles Pires. 2016c. In: Diário Oficial no $26864 . \quad$ Disponível em: <https://www.iomat.mt.gov.br/verpdf/14629/\#/p:17/e:14629?find=Comit\%C3\%AA\%20de\%20Bacia>. Acesso em: 17 mar. 2018.

. Conselho Estadual de Recursos Hídricos. Resolução n. 94 de 16 de Maio de 2017. Aprova o quadro de metas do PROGESTÃO para o período de 2017 a 2021. 2017. In: Diário Oficial n. 26567. Disponível em: < https://is.gd/hsWMbl >. Acesso em: 11 Jan. 2018.

. Conselho Estadual de Recursos Hídricos. Resolução no 106, de 10 de maio de 2018. Institui - Comitê de Bacia Hidrográfica dos Afluentes do Alto Araguaia. In: Diário Oficial no 27264. https://www.iomat.mt.gov.br/ver-pdf/15193/\#/p:16/e:15193?find=Comit\%C3\%AA\%20de\%20Bacia

MEDEIROS, P. C; CANALI, N. E. Relações de poder e resistências na gestão territorial das bacias hidrográficas no estado do Paraná. GEOUSP: Espaço e Tempo (Online), n.31,p.04-17,2012. https://doi.org/10.11606/issn.2179-0892.geousp.2012.74265

MORENGO, J. A.; ALVES, L. M. Crise hídrica em São Paulo em 2014: seca e desmatamento. GEOUSP: Espaço e Tempo (Online), v. 19, n. 3, p. 485-494, 2015. https://doi.org/10.11606/issn.2179-0892.geousp.2015.100879

MORENO, G.; HIGA, T. C. S. Geografia de Mato Grosso. Cuiabá: Entrelinhas, 2005. 296p.

MORETTI, E. C.; MARINHO, V. L. F. A Gestão De Recursos Hídricos no Brasil e os Comitês De Bacias Hidrográficas - A Experiência Do CBH-Miranda (MS). Revista da ANPEGE, v. 12, n. 17, p. 123-140, 2016.

https://doi.org/10.5418/RA2016.1217.0006

MORETTI, E. C.; MARINHO, V. L. F. Os caminhos das águas: As políticas públicas ambientais e criação dos Comitês de Bacias Hidrográficas. Geosul, v. 28, n. 55, p. 123-142, 2013. https://doi.org/10.5007/2177-5230.2013v28n55p123 
NETO, J. C. C. A crise hídrica no Estado de São Paulo. GEOUSP: Espaço e Tempo (Online), v. 19, $\begin{array}{lllll}\text { n. } 3, & \text { p. } & 479-484, & \end{array}$ https://doi.org/10.11606/issn.2179-0892.geousp.2015.101113

NOQUELLI, L. H. M. Proposta de regulamentação do enquadramento dos corpos d'água do estado de Mato Grosso: subsídios à gestão dos recursos hídricos . 2016. 144p. Dissertação (Mestrado). Universidade Federal de Mato Grosso - UFMT.

OLIVEIRA, L. B.; KOETZ, L. C. E.; PÉRICO, E.; MAZZARINO, J. M.; GRAVE, M. T. Q. Gerenciamento comunitário de recursos hídricos, uma questão de saúde: a água que temos e a água que queremos: percepção dos usuários de sociedades de água em um município rural da sub-bacia hidrográfica do Forqueta, RS. Ambiência, v. 11, n. 2, p. 359-374, 2015.

PORTO, M. F.; PORTO, R. L. L. Gestão de bacias hidrográficas. Estudos avançados, v. 22, n. 63, p. 43-60, 2008. https://doi.org/10.1590/S0103-40142008000200004

POSSAVATZ, J.; ZEILHOFER, P.; PINTO, A. A.; TIVES, A. L.; DORES, E. F. G. D. C. Resíduos de pesticidas em sedimento de fundo de rio na Bacia Hidrográfica do Rio Cuiabá, Mato Grosso, Brasil.

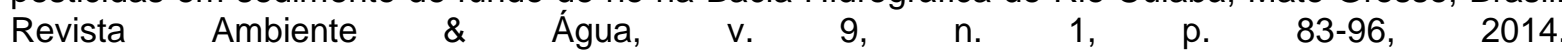
https://doi.org/10.4136/ambi-agua.1263

QGIS DEVELOPMENT TEAM. QGis Geographic Information System- Open Source Geospatial Foundation, 2017. Disponível em: < http://qgis.osgeo.org/pt_BR/site/ >. Acesso em: 19 Fev. 2018.

ROCHA, L. R. L. A área de influência da BR 163 no Estado do Mato Grosso: desmatamento e sua relação com a saúde ambiental no município de Guarantã do Norte. Universitas: Relaçõe Internacionais, v. 13, n. 1, 2015. https://doi.org/10.5102/uri.v13i1.3383

SCANTIMBURGO, A. O avanço do agronegócio e o aumento dos conflitos pelo uso da água. Leituras de Economia Política, n. 24, p. 27-54, 2016.

SEMA - SECRETARIA DE ESTADO DE MEIO AMBIENTE DO ESTADO DE MATO GROSSO. Termo de Colaboração n. 1486 de 23 de outubro de 2018 . Disponível em: <http://www.cppantanal.org.br/2018/images/docs/termodcolaboracaocppsema.pdf>. Acesso em: 20/01/2020.

Organograma da Secretaria de Estado de Meio Ambiente. 2018. Disponível em: <

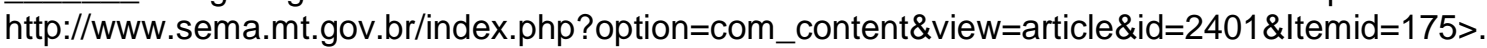
Acesso em: 22 Out. 2018.

SERIGATTO, E. M. Delimitação automática das áreas de preservação permanente e identificação dos conflitos de uso da terra na bacia hidrográfica do rio Sepotuba-MT. 2006. 188p. Tese (Doutorado). Universidade Federal de Viçosa, Viçosa - MG.

SOUZA, A. P.; MOTA, L. L.; ZAMADEI, T.; MARTIN, C. C.; ALMEIDA, F. T.; PAULINO, J. Classificação climática e balanço hídrico climatológico no estado de Mato Grosso. Nativa, v. 1, n. 1, p. 34-43, 2013. https://doi.org/10.14583/2318-7670.v01n01a07

SOUZA, H. M. L..; NUNES, J. R. S. Avaliação dos parâmetros físico-químicos e bacteriológicos do córrego Figueira pertencente à microbacia do Queima-Pé de Tangará da Serra/MT. Engenharia Ambiental - Espírito Santo do Pinhal, v. 5, n. 2, p. 110-124, 2008.

SOUZA, M. B.; SILVEIRA, R. C. E. Gestão de Recursos Hídricos: uma análise do Plano Municipal de Saneamento Básico de Xangri-Lá/RS. Redes, v. 21, n. 2, p. 182-197, 2016. https://doi.org/10.17058/redes.v21i2.7873

SPINOLA, C. D. A.; VITORIA, F.; CERQUEIRA, L. A Lei das Águas e o São Francisco: os Limites da Gestão Descentralizada dos Recursos Hídricos no Brasil. Revista de Desenvolvimento Econômico RDE, v. 18, n. 33, p. 70-90, 2016. https://doi.org/10.21452/rde.v1i33.4176 
TANGARÁ DA SERRA. Decreto n.ํ 351, de 20 de Outubro de 2016. Declara situação de emergência neste município, afetado por estiagem. Disponível em: < https://is.gd/yNYJbt >. Acesso em: 29 Dez. 2018.

Recebido em: 02/05/2019

Aceito para publicação em: 25/11/2019 